\title{
Management strategy evaluation of pheromone-baited trapping techniques to improve management
}

of invasive sea lamprey

Authors: Heather A. Dawson ${ }^{* a}$, Michael L. Jones ${ }^{b}$, Brian J. Irwin ${ }^{c}$, Nicholas S. Johnson ${ }^{\text {d }}$, C. Michael Wagner ${ }^{\mathrm{e}}$, Melissa Szymanski ${ }^{\mathrm{a}}$

${ }^{a}$ Department of Biology, University of Michigan-Flint, 264 Murchie Science Building, Flint, MI 48502,

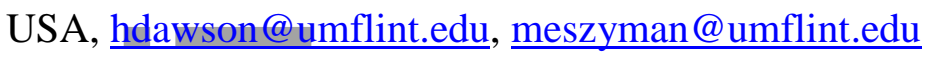

${ }^{\mathrm{b}}$ Quantitative Fisheries Center, Department of Fisheries and Wildlife, Michigan State University, 13 Natural Resourees Building, East Lansing, MI 48824, USA, jonesm30@msu.edu

${ }^{c}$ U.S. Geological Survey, Georgia Cooperative Fish \& Wildlife Research Unit, Warnell School of Forestry and Natural Resources, University of Georgia, 180 E. Green St., Athens, GA 30602, USA, irwin@uga.edu

${ }^{\mathrm{d}}$ U.S. Geological Survey, Great Lakes Science Center, Hammond Bay Biological Station, 11188 Ray Rd., Millersburg, MI 49759, USA, njohnson@usgs.gov

e Department of Fisheries and Wildlife, Michigan State University, 13 Natural Resources Building, East Lansing, MI 48824, USA, mwagner@msu.edu

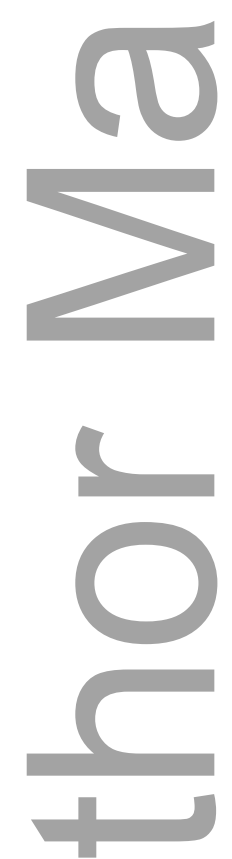

*Corresponding author at: Department of Biology, University of Michigan-Flint, 264 Murchie Science Building, Flint, MI 48502, USA. Tel.: + 1810762 3360. Fax: 1810762 3310. Email address: hdawson@umflint.edu

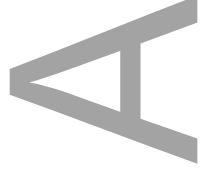

This is the author manuscript accepted for publication and has undergone full peer review but has not been through the copyediting, typesetting, pagination and proofreading process, which may lead to differences between this version and the Version of Record. Please cite this article as doi: $\underline{10.1111 / \mathrm{nrm} .12096 .}$.

This article is protected by copyright. All rights reserved. 
ABSTRACT. We applied a management strategy evaluation (MSE) model to examine the potential cost-effectiveness of using pheromone-baited trapping along with conventional lampricide treatment to manage invasive sea lamprey. Four pheromone-baited trapping strategies were modeled: (1) stream activation wherein pheromone was applied to existing traps to achieve $10^{-12} \mathrm{~mol} \cdot \mathrm{L}^{-1}$ in-stream concentration, (2) stream activation plus two additional traps downstream with pheromone applied at 2.5 $\mathrm{mg} \cdot \mathrm{hr}^{-1}$ (reverse-intercept approach), (3) trap activation wherein pheromone was applied at $10 \mathrm{mg} \cdot \mathrm{hr}^{-1}$ to existing traps, and (4) trap activation and reverse-intercept approach. Each new strategy was applied, with remaining funds applied to conventional lampricide control. Simulating deployment of these hybrid strategies on fourteen Lake Michigan streams resulted in increases of 17 and 11\% (strategies 1 and 2) and decreases of 4 and $7 \%$ (strategies 3 and 4) of the lakewide mean abundance of adult sea lamprey relative to status quo-MSE revealed performance targets for trap efficacy to guide additional research because results indicate that combining lampricides and high efficacy trapping technologies can reduce sea lamprey abundance on average without increasing control costs.

KEY WORDS: Management strategy evaluation, integrated pest management, Laurentian Great Lakes, pest control, recruitment dynamics, structured decision making.

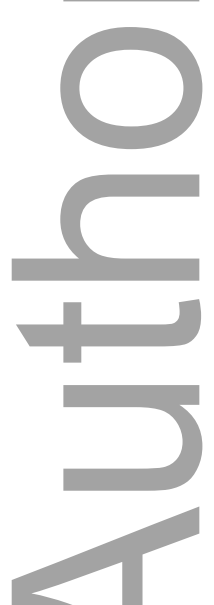

1. Introduction. Fisheries management decisions often involve choices about allocation of limited resources that are made in the face of considerable uncertainty, yet frequently lack a clear demonstration that the anticipated outcome will warrant the public investment. Models that attempt to realistically 
simulate the outcomes of competing management alternatives can provide valuable insight into the possible consequences of a decision. In recent years, models that simulate the entire management process, known as Management Strategy Evaluation (MSE) operating models, have been used widely for this purpose in marine commercial fishery management (Punt 2006; Butterworth 2007). These models typically seek to describe management and assessment processes and are used to forecast consequences of management strategies in support of structured decision making where key uncertainties are identified and evaluated relative to specified objectives (Irwin et al. 2011). Failing to account for uncertainty may lead to unrecognized risks or poorly understood probabilities of undesirable outcomes relative to public policy goals (Jones and Bence 2009). By using an MSE model to compare the projected performance of alternative management strategies, decision makers can (1) make better-informed choices, (2) objectively consider where important trade-offs might arise concerning allocation of limited resources, and (3) clearly communicate the scientific basis of final decisions to interested stakeholders.

MSE models evaluate the performance of different management procedures under a range of projected future circumstances (Bunnefeld et al. 2011). In the context of pest-control, a model-based evaluation can be an important step following the discovery of a new option that has proven viable in small-scale testing and may be scalable to levels that produce management benefits. Integration of the proposed option into modeled strategies that depict the full management process allows for direct comparison of program efficacy and cost-effectiveness of the modeled strategies with the status quo, and explicit consideration of trade-offs given uncertain future conditions. MSE can provide validation for the decision to implement, or not to implement, an alternative control option by creating a framework for decision making that is not reliant on informal extrapolation of limited experimental results. By comparing the performance of a range of alternative strategies under plausible scenarios upfront, the response of the system can be compared with the desired goals and evaluated in advance of implementation (Bunnefeld et al. 2011). Formally evaluating a range of management options will also increase the chances that fishery managers will adopt changes to improve system performance (McAllister et al. 1999). 
Common decisions confronted by managers include whether to continue with the status quo, try a novel approach, or refine a current management strategy in an effort to achieve management goals more effectively. Here, we demonstrate the value of MSE in guiding such choices using the integrated pest management (IPM) program implemented by the Great Lakes Fishery Commission (GLFC) to control invasive sea lamprey (Petromyzon marinus) in the Laurentian Great Lakes. Managers implementing IPM must decide how to allocate resources among implementation of status quo control strategies, research, development, implementation of novel pest management strategies, and refinement of existing management strategies. IPM requires the use of compatible or synergistic combinations to reduce pest populations and maintain them at levels below those causing environmental loss or damage (Birch et al. 2011). MSE can compare a range of hybrid strategies (using a combination of management tactics) through the use of a model that simulates the relative success of strategies at reducing pest populations, while accounting for control costs. When a program invests in the development of a strategy, there can be pressure to implement that strategy due to the prior investment in developing the strategy. MSE can be useful for objectively determining whether implementation is justified, and can provide efficacy targets (of a strategy) for researchers to pursue when developing or refining control strategies for implementation.

With the goal of controlling sea lamprey populations to enhance survival and reproduction of desirable fishes, the GLFC allocates resources among pesticide control (chemicals that selectively kill larval lampreys, referred to as lampricides), alternative controls (i.e., control strategies alternative to traditional use of lampricides in streams), population assessment, as well as research and development to improve control practices (GLFC 2011; Irwin et al. 2012). The development of alternative technologies to control Great Lakes sea lamprey is a centerpiece of the GLFC vision for sea lamprey management (GLFC 2011), and recently researchers have developed methods to improve trapping of adult sea lamprey by baiting traps with a synthesized pheromone (Wagner et al. 2006; Johnson et al. 2013). Traps target both migrating subadults and sexually-mature adults; hereafter referred to as adult sea lampreys. Management-scale field tests have used the synthesized male mating pheromone component, $7 \alpha, 12 \alpha, 24$-trihydroxy-3-one-5 $\alpha$-cholan- 
24-sulfate (3kPZS), as bait in both traditional barrier-integrated traps (Johnson et al. 2013) and a novel approach where traps are placed downstream of barriers to intercept uncaptured maturing sea lamprey as they reverse course and seek downstream spawning areas (Wagner and Thomas 2010). These trials have helped produce data on the cost and efficacy (defined as the proportion of adult sea lamprey from a migrating population in a stream removed by traps) of using partial pheromones to enhance trap capture. Additionally, 3kPZS was recently registered with U.S. EPA and Health Canada as the first vertebrate pheromone biopesticide. We evaluated the expected consequences of incorporating pheromone-baited trapping into the sea lamprey control program by examining projected changes in the future abundance of adult sea lamprey vs. maintaining status quo management in an MSE model. Our objectives in this study were to 1) update and refine an existing sea lamprey MSE model to provide an effective tool to rapidly assess the costs and benefits of deploying pheromone-baited trapping strategies as part of an integrated control program; and 2) use the model to determine the necessary costs and efficacies of an enhanced trapping strategy to allow an integrated (trapping + lampricide) control program to outperform the current control program.

\section{Methods.}

2.1. Model overview. A stochastic age-structured population model was used to forecast the effect of different control strategies on the future abundance of sea lamprey in the Great Lakes. Our model was derived from the operating model previously described in Jones et al. (2009); a brief overview of the operating model is provided here. The operating model includes a biological model of the sea lamprey life cycle, an observation model that incorporates imperfect population assessments (i.e., observation uncertainty) and a management model that implements management actions according to a pre-defined management procedure. The model forecasts changes in abundance over a 100-year time horizon for the full life cycle of the populations of sea lamprey occupying each of the Great Lakes and its tributaries. The 
complete set of sea lamprey-producing streams for each lake was explicitly represented in this model, following the approach used by the GLFC for lampricide control, which divides large streams into reaches for which independent lampricide treatment decisions can be made. The model includes uncertainty in biological processes (recruitment and growth), assessment of larval abundance in reaches considered for treatment, and implementation of lampricide control. This model was successfully applied to evaluate allocation of budgetary resources between larval population assessment and other management actions (Jones et al. 2009), conduct a preliminary assessment of integrated control strategies (i.e., lampricide and alternative control [specifically adult-targeted alternative control]; Dawson 2007), and generate estimates of economic injury levels (Szlai et al. 2005; Irwin et al. 2008).

Here, we limited our analysis to Lake Michigan - where several of the 3kPZS study streams were located - and modified the operating model to incorporate pheromone-baited trapping as an alternative management option to status quo sea lamprey management. Status quo control includes application of lampricides, reliance on the existing network of physical barriers that block migrating adults, and historical trapping of adults in streams. The operating model implicitly includes existing barriers by excluding areas upstream of these barriers from consideration for control. Only reaches that are currently candidates for lampricide control are considered for control of adult sea lamprey. Historical trapping is included by reducing the number of adult sea lamprey in streams by the historical efficacy of traps in those streams. Thus, status quo management actually refers to a strategy that includes lampricide treatments plus all existing alternative controls (i.e., existing barriers and traps). Below, we describe adjustments made to the Jones etal.(2009) model to incorporate pheromone-baited trapping as an alternative management option, with all other updates (i.e., changes in the way sea lamprey control agents assess larval populations in streams and rank streams for treatments) described in the appendix. Values for all relevant model parameters are provided in Table 1. 
2.2. Modeling a new control tactic. To incorporate pheromone-baited trapping strategies into the management model, we needed to adjust the number of adult sea lamprey that actually spawn in a river reach to account for removals due to trapping:

$$
\hat{\mathrm{S}}_{i, t}=S_{i, t}\left(1-\hat{\mathrm{E}}_{j}\right)
$$

where $\hat{S}_{i, t}$ is the adjusted number of adult sea lamprey left in each reach after trapping, $S_{i, t}$ is the number of adult sea lamprey entering each reach, and $\hat{\mathrm{E}}_{j}$ is the adjusted trap efficacy in each stream $j$ (stream $j$ includes all the reaches, $i$, of a particular stream). Trapping reduces sea lamprey in all reaches of a stream, as traps are often integrated with barriers that are placed close to the mouth of a stream. $\hat{S}_{i, t}$ then replaces $S_{i, t}$ to calculate recruitment of larvae in each reach using two stochastic stock-recruitment functions, one for streams classified as "regular producers" and one for streams classified as "irregular producers". Ricker stock-recruitment parameters were obtained from Dawson and Jones' (2009) analysis of 37 streams (97 stream-years) for which estimates of spawner and recruit abundances were available. Dawson and Jones (2009) found that streams classified as "regular producers" by sea lamprey control agents tended to have higher productivity, measured as a significant positive offset in $\ln ($ Recruits/Spawners) at low spawner abundance, relative to so-called "irregular producers", even after accounting for differences among streams in the amounts of preferable and acceptable habitat. Regular producers are streams that require treatment on a consistent cycle of 3-5 years, while irregular producers are not as consistent.

The efficacy of the traps in a stream was modeled as

$E_{j}=\left(E_{H_{j}}+\varepsilon_{H}\right)+\left(E_{E_{j}}+\varepsilon_{E}\right)(2)$

where $E_{H_{j}}$ is the 10-year average historical efficacy of unbaited traps (Table 2) already serviced and operated by control agents, and $\varepsilon_{H}$ is a normally distributed random deviate with mean 0 and standard deviation 0.142 , calculated from data on inter annual variation in trapping efficacy (J. Barber, U.S. Fish and Wildlife Service, personal communication). $E_{E_{j}}$ is the enhanced efficacy of traps due to the application 
of $3 \mathrm{kPZS}$ (Table 3 ) that varied depending on the management strategy being simulated, and $\varepsilon_{E}$ is a normally distributed random deviate with mean 0 and standard deviation 0.135 , calculated from Johnson et al. (2013). We constrained $E_{j}$ (a proportion) to follow a truncated normal distribution, a segment of a normal distribution between $[0,1]$.

Because sea lamprey control agents calculate trapping efficacy in each stream and year by marking and releasing a proportion of adult sea lamprey that are trapped, we also needed to adjust trapping efficacy to account for animals that are marked and released but never recaptured (mark-recapture losses). First, we determined the proportion of animals that were released, but not recaptured (unrecovered).

$U_{j}=E_{j} M_{j} N R_{j}$

where $M_{j}$ is the 5-year average proportion of animals caught in traps that were marked and released, and $N R_{j}$ is the 5-year average proportion of animals caught in traps that were marked but not recaptured (Table 2; J. Barber, U.S. Fish and Wildlife Service, personal communication). We then adjusted trapping efficacy to account for mark-recapture losses.

$$
\hat{\mathrm{E}}_{j}=E_{j}-U_{j},(4)
$$

Sea lamprey control agents mark and release a maximum of 50 adult sea lamprey trapped in each stream each day. Larger streams are likely to reach that maximum before enhanced trapping efficacy is applied (i.e., at historical trapping efficacy). Therefore, historical trapping efficacy was adjusted to account for mark-recapture losses in all streams, while total trapping efficacy (historical + enhanced trapping efficacy) was adjusted to account for mark-recapture losses only in streams with a drainage area of $<2000 \mathrm{~km}^{2}$ (Table 2).

We evaluated two alternatives for applying 3kPZS (i.e., stream activation or trap activation) combined with two approaches for trapping design (i.e., standard trapping or reverse-intercept trapping) for a total of four hybrid management strategies (each using both lampricides and pheromone-baited trapping), and which were also compared with status quo sea lamprey management in Lake Michigan (Table 3). The 
stream activation alternative assumes that $3 \mathrm{kPZS}$ increases trap efficacy by increasing the number of adult sea lamprey that migrate upstream to the barrier each night (increase encounters; therefore $3 \mathrm{kPZS}$ should activate the entire stream discharge; Table 3). The trap activation alternative assumes that $3 \mathrm{kPZS}$ increases trap efficacy by increasing the number of adult lamprey that enter the trap after encountering the trap (thus 3kPZS should activate only the trap opening; Table 3; Johnson et al. 2015). Standard trapping baits existing adult sea lamprey control traps, while the reverse-intercept approach baits existing traps and two additional traps placed downstream (Table 3). For each new strategy, we simulated deployment of pheromone-baited trapping in 14 of 16 currently trapped streams and their reaches in Lake Michigan (Figure 1; Table 2). Two currently trapped streams were excluded from the analysis upon advice from sea lamprey control agents. In these two streams, fyke nets were used as traps, which prohibits the automatic deployment of a polyethylene glycol 3kPZS emitter into the trap. We simulated hybrid management strategies where we first allocated the budget apportioned to sea lamprey control to the costs of deployment of the pheromonebaited trapping tactic, and then used the remaining funds for lampricide control. For status quo management, the entire budget apportioned to sea lamprey control was allocated to lampricide treatments. This tested the cost-effectiveness of using some pheromone-baited trapping with lampricide treatments, as we measured whether we can still produce less adult sea lamprey by diverting some control budget funds from lampricide control (by treating less streams) to pheromone-baited trapping.

Standard trapping was considered a refinement of an existing management approach because all traps (barrier-integrated or portable traps, described above) that were currently deployed and serviced on these streams were assumed to have increased efficacy because of pheromone baiting (Table 3). In a recent management experiment on eight Great Lakes streams, yearly trapping efficacy for standard trapping was significantly higher during the three years $3 \mathrm{kPZS}$ was applied to achieve a $10^{-12} \mathrm{~mol} \cdot \mathrm{L}^{-1}$ in-stream concentration, although variability around the mean response was high ( $-40 \%$ to $+40 \%)$, with an overall mean increase in efficacy of 9\% above historical efficacy (11-year average; Johnson et al. 2013; Johnson et 
al. 2015). Thus, we assumed that standard trapping using the stream activation alternative could result in a $9 \%$ increase in trapping efficacy (Table 3).

Reverse-intercept trapping was considered a novel approach because, along with baiting existing traps, two additional traps were baited and placed between the barrier and the spawning grounds. Migrating sea lamprey have been observed pooling at or near barriers until maturation and the time of spawning approaches. Sea lamprey not captured in traps at or near barriers then reverse course and head downstream to locate spawning habitat and mates. By placing additional traps between the barrier and spawning grounds as the time of spawning approaches, which usually occurs during the final days of the standard trapping season, sea lamprey will pass through the $3 \mathrm{kPZS}$ odor plumes emitted by these traps before encountering any natural male pheromone and thereby should be more vulnerable to capture. We term this approach a "reverse-intercept" due to the reversal in the direction of movement as opposed to the dam-face traps which simply "intercept" an upstream movement. Reverse-intercept trapping was validated in a management-scale experiment using PIT-tagged sea lamprey and a relatively low 3kPZS application rate to the additional traps (Wagner and Thomas 2010). Reverse-intercept trapping captured an additional 9\% of sea lamprey not captured by standard trapping (Wagner and Thomas 2010) after the standard trapping season had concluded. We assumed these effects would be additive, such that reverse-intercept trapping using the stream activation alternative could produce an $18 \%$ increase in trapping efficacy (Table 3 ).

In the Johnson et al. (2013) management experiment on eight Great Lakes streams, streams with intermediate discharge levels among the streams they studied ( 6 to $\left.10 \mathrm{~m}^{3} \cdot \mathrm{s}^{-} 1\right)$ experienced increases of $\sim 25 \%$ in trap efficacy above historical efficacy (11-year average) using standard trapping when $\sim 100 \mathrm{mg}$ of $3 \mathrm{kPZS}$ was applied per night (to achieve a final in-stream concentration of $10^{-12} \mathrm{~mol} \cdot \mathrm{L}^{-1}$ in these streams). Thus, we assumed that standard trapping using the trap activation alternative could result in a $25 \%$ increase in trapping efficacy (Table 3). Reverse-intercept trapping using the trap activation alternative was assumed to provide another $9 \%$ increase in trapping efficacy (producing a total increase of $34 \%$; Table 3 ). 
The overall cost of a pheromone-baited trapping strategy includes research and development costs, registration of $3 \mathrm{kPZS}$ with the appropriate authorities, cost of $3 \mathrm{kPZS}$, cost of deployment, and cost of monitoring the efficacy of those tactics. In our analysis we focused only on the cost of $3 \mathrm{kPZS}$ and the deployment costs, as the other costs are either not related to the scale of deployment (i.e. they are "fixed" costs) or are not separable from other program activities (e.g., efficacy monitoring). Unbaited trapping of adult sea lamprey is currently used as an assessment method in select streams across the Great Lakes, so for this analysis the costs of operating unbaited traps are not considered control costs. However, we assume that additional costs associated with use of pheromone-baited trapping are control costs and were thus incorporated into our trade-off analysis as described below. In other words, our analysis here does not consider the potential benefits of deploying more unbaited traps at new locations (or eliminating trapping at existing locations); we focus on the consequences of adding baiting to existing trapping operations and adding the reverse-intercept approach to currently trapped streams.

To obtain realistic cost estimates of $3 \mathrm{kPZS}$ and its deployment we consulted previous research using pheromone-baited trapping (Johnson et al. 2013) and contacted sea lamprey control agents. The cost of pheromone-baited trapping per stream is calculated by

$C_{E_{j}}=C_{C_{j}}+C_{D_{j}}(5)$

where $C_{C_{j}}$ is the cost of $3 \mathrm{kPZS}$ per stream, and $C_{D_{j}}$ is the cost of deployment of pheromone-baited trapping per stream. The cost of $3 \mathrm{kPZS}$ per stream is calculated by

$C_{C_{j}}=A_{j} C_{A}\left(T_{j} D_{S}+T_{N_{j}} D_{R}\right)(6)$

where $A_{j}$ is the amount of attractant $(3 \mathrm{kPZS})$ in mg needed for each trap each day, which sometimes varied by stream and by the management strategy being tested. $C_{A}$ is the cost of $3 \mathrm{kPZS}$ per mg, $T_{j}$ is the number of existing traps, $D_{S}$ is the number of trapping days in the standard trapping approach, $T_{N_{j}}$ is the number of additional traps, and $D_{R}$ is the number of trapping days in the reverse-intercept approach.

The cost of deployment of pheromone-baited trapping per stream is calculated by 
$C_{D_{j}}=C_{T_{N_{j}}}+C_{B_{j}}+C_{L_{j}},(7)$

where $C_{T_{N_{j}}}$ is the cost of deploying additional traps, $C_{B_{j}}$ is the staff cost of baiting traps, and $C_{L_{j}}$ is the staff cost of capturing more sea lamprey. The cost of deploying additional traps per stream is calculated by $C_{T_{N_{j}}}=T_{N_{j}} C_{A T_{N}}+T_{N_{j}} p_{S} C_{S_{j}} D_{R}+C_{A_{j}}$

where $C_{A T_{N}}$ is the annual cost of an additional trap. The annual cost of a new trap, $C_{A T_{N}}$, is the cost of the trap divided by the years of expected life of the trap. The $p_{S}$ is the proportion of staff day needed to service a single trap each day. The cost of a staff day, $C_{S_{j}}$, varied by stream depending on whether an outside contractor or U.S. Fish and Wildlife Service (USFWS) personnel serviced the trap(s). $C_{A_{j}}$ is the annual project staff cost for new projects for USFWS for each stream where pheromone-baited trapping was applied, which should cover the cost to set and remove additional traps among other costs. If no additional traps were used then the above equation becomes $C_{T_{N_{j}}}=C_{A_{j}}$.

The staff cost of baiting traps in a stream is calculated by

$C_{B_{j}}=p_{B} C_{S_{j}}\left(T_{j} D_{S}+T_{N_{j}} D_{R}\right)(9)$

where $p_{B}$ is the proportion of staff day needed to bait a single trap each day.

The staff cost of capturing more sea lamprey per stream is calculated by

$C_{L_{j}}=p_{L} C_{S_{j}}\left(S_{i, t} E_{E_{j}} / 100\right)(10)$

where $p_{L}$ is the proportion of staff day needed to process 100 more sea lamprey each day.

2.3. Model calibration and simulations. Prior to evaluating pheromone-baited trapping, the model was calibrated as described in Jones et al. (2009), using recent control expenditures (7-year annual lampricide budgets, 2004-2010 in our study) and recent observed values of abundance for adult sea lamprey (7-year mean, 2006-2012 in our study), all provided by the GLFC. A two-year lag between the calculations of calibration target abundance and values of the budget apportioned to sea lamprey control reflects the 
time lag between a lampricide application, which targets larvae, and its effect on adult abundance. The goal of the calibration process was for the simulation model to approximate adult sea lamprey abundances close to recent observations when using the budget apportioned to sea lamprey control that corresponds to actual recent expenditures in Lake Michigan. An adjustment from Jones et al. (2009) is that we calibrated the model based on status quo management of Lake Michigan, which included both lampricide control and unbaited trapping. Lampricide control was simulated as described in the appendix. Unbaited trapping was simulated by applying the 10-year average historical trap efficacy, $E_{H_{j}}$, to all 16 traps in the lake already serviced and operated by control agents in each year of a simulation (Table 2). This adjusted the number of sea lamprey that actually spawn in a river reach as described by equation 1 . Because unbaited trapping is considered an assessment method rather than a control method, the calibration budget was the same as the budget apportioned to sea lamprey control. We used 5000 simulations with a 100 year time horizon, and the mean abundance of adult sea lampreys was recorded for the final ten years $(t=91-100)$ for each set of 5 000 simulations, and then the mean abundance was calculated across all simulations. Larval survival was the parameter we adjusted during calibration until the model performed well at projecting the recent observed average value of abundance for adult sea lamprey of 100800 in Lake Michigan for status quo management using an average recent budget apportioned to sea lamprey control of $\$ 2.3$ million (M. Siefkes, Great Lakes Fishery Commission, personal communication).

We wished to assess the conditions wherein use of pheromone-baited trapping as a control tactic would be cost-effective. That is, does using some pheromone-baited trapping result in lower adult sea lamprey abundance relative to status quo management under the same budget? Thus, after comparing the four hybrid management strategies (stream and trap activation using standard and reverse-intercept trapping approaches) to status quo management using the current estimates of cost and efficacy of pheromone-baited trapping (Table 1), we then applied incrementally larger adjustments to efficacy to determine how much of an improvement in trapping efficacy is necessary, given current cost estimates, to offset the effect of the corresponding reduction in lampricide use. Additionally, at current estimates of efficacy, we incrementally 
adjusted costs downward to determine how much of a reduction in costs is necessary to offset the corresponding reduction in lampricide use. For each of the four hybrid management strategies, we also evaluated the reduction in cost of $3 \mathrm{kPZS}$ or the increase in trap efficacy that would be required to reduce the forecasted abundance of adult sea lamprey in Lake Michigan by $10 \%$ from the level achieved by status quo management.

3. Results. Performance of hybrid strategies relative to status quo management varied substantially depending on whether the stream or trap was activated with pheromone, and somewhat on the trapping approach used. Using the stream activation alternative at the recent budget apportioned to sea lamprey control (\$2.3 million) resulted in a higher forecasted mean abundance of adult sea lamprey than was observed for status quo management (Figure 2), with at least $50 \%$ of the simulations having forecasted abundance of adult sea lamprey below the status quo abundance (i.e., median forecasted abundance was lower than the mean forecasted abundance of adult sea lamprey). Using the trap activation alternative at the recent budget apportioned to sea lamprey control resulted in lower forecasted mean abundance of adult sea lamprey than was observed for status quo management (Figure 2), and in at least $61 \%$ of the simulations the forecasted abundance of adult sea lamprey was lower than the status quo abundance.

Increases in efficacy had a greater effect on sea lamprey abundance than did comparable decreases in cost of $3 \mathrm{kPZS}$ per mg, but reducing costs had a greater effect on adult sea lamprey abundance when simulating the stream activation relative to the trap activation alternative. For the stream activation alternative, trapping efficacy would have to be increased by $38 \%$ from historical trapping efficacy using the reverse-intercept (18\% current estimate plus 20\%) or standard trapping approach (9\% current estimate plus $29 \%$ ) to offset the reduction in lampricide use and perform as well as status quo management (Table 4). Alternatively, the cost of $3 \mathrm{kPZS}$ per milligram would have to be reduced to $\$ 0.03$ from $\$ 0.75$ to fare as well as status quo management under the stream activation alternative. Cost of the stream activation alternative was higher than the trap activation alternative because more pheromone is required to activate 
the entire stream discharge relative to activating the trap. For the trap activation alternative, the increase in trapping efficacy from historical efficacy would only have to be $14 \%$ using the reverse-intercept or standard trapping approach to offset the reduction in lampricide use and perform as well as status quo management, which was lower than the current estimate of the increase in trapping efficacy (25\% for standard trapping and $34 \%$ for reverse-intercept trapping) that is thought to be achieved using this alternative (Table 4).

Realizing reductions of at least $4 \%$ in abundance of adult sea lamprey relative to status quo management was achievable when incorporating pheromone-baited trapping into the control program. The trap activation alternative using the reverse-intercept approach achieved a $7 \%$ reduction in abundance of adult sea lamprey relative to status quo management at current estimates of efficacy and cost. Achieving a $10 \%$ reduction in abundance using the trap activation alternative required a small increase in trapping efficacy from current estimates (34\% current estimate plus $8 \%$ for reverse-intercept trapping; Table 4). Achieving a $10 \%$ reduction in abundance using the stream activation alternative required a large increase in trapping efficacy from current estimates (18\% current estimate plus $42 \%$ for reverse-intercept trapping; Table 4). Pheromone-baited trapping aims to remove adult sea lamprey in an effort to reduce subsequent recruitment, but effectiveness of this tactic is hindered by the loss of adult sea lamprey that are marked and released and never recaptured. For example, if no adult sea lamprey were "lost" from performing markrecapture, the trap activation alternative using the reverse-intercept approach would achieve a $9 \%$ greater reduction in abundance of adult sea lamprey (for a total of a $16 \%$ reduction from status quo) relative to status quo management at current estimates of efficacy and cost. For the trap activation alternative, reductions in the cost of $3 \mathrm{kPZS}$ did little to change the abundance of adult sea lamprey that was realized; reducing the cost of $3 \mathrm{kPZS}$ per milligram from $\$ 0.75$ to $\$ 0.20$ when employing standard trapping reduced abundance by less than $1 \%$. However, for the stream activation alternative, reductions in the cost of $3 \mathrm{kPZS}$ had a larger effect; when employing standard trapping a reduction in the cost of 3kPZS per milligram from $\$ 0.75$ to $\$ 0.20$ reduced abundance by $11 \%$. 
4. Discussion. Based on current estimates of costs and efficacy for pheromone-baited trapping, our simulations indicate only the trap activation alternative warrants further investigation. The addition of large quantities of pheromone necessary for the stream-activation option was not cost-effective relative to current management procedures. To further investigate the trap activation alternative it would be valuable to determine the relative importance of pheromone concentration at the entrance to the trap, versus downstream from the trap. Further evaluations could include field trials where $3 \mathrm{kPZS}$ application rate is varied across streams irrespective of discharge with the objective to determine the relationship between $3 \mathrm{kPZS}$ application rate and increases in trap efficacy to further inform evaluation of pheromone-baited control tactics. Our simulation analysis suggests that the cost effectiveness of a "baited-trap" strategy will depend considerably on this, especially for larger streams where maintaining adequate downstream concentrations requires large amount of pheromone. Uncertainty also exists concerning which mechanism is driving the increase in trap efficacy with the application of 3kPZS (e.g., increased encounters with traps or increased entries and retention after an encounter), and research in this area may help inform the potential for pheromone application to further increase trapping efficacy. In addition to evaluation, the MSE approach can be used to generate efficacy targets for research and development programs, just as our research provides target efficacies for researchers to attempt to reach in field trials of pheromone-baited trapping.

The annual survival rate for larval sea lamprey was adjusted to $37 \%$ in order to calibrate the model, which is reasonable given the few measures of larval sea lamprey survival recorded. Weise and Pajos (1998) estimated annual mortality (over a four-year period) of the second cohort to colonize a Great Lakes tributary following a lampricide treatment to be 39\%. More recently, Johnson et al. (2014) modeled survival of tagged larvae reintroduced into Great Lakes tributaries following lampricide treatments to be $57 \%$. However, this is for larger larvae, which may have higher survival rates than age-0, 1 or 2 larvae. While predicting the results of a management action is often very uncertain because the dynamics of ecosystems are complex and poorly understood (Sainsbury et al. 2000), one of the primary goals of 
evaluating fishery management systems through simulation is to identify options that allow a management objective to be met (i.e., obtaining the highest yields possible, achieving the greatest reduction in pest populations) at an acceptable level of risk (McAllister et al. 1999). Our model can provide the GLFC with specific performance criteria (target costs and efficiencies) necessary to justify the deployment of pheromone-baited trapping strategies when risks are considered. Our analysis indicates that none of the strategies we considered is certain to outperform the alternatives, even though some strategies are, on average, more cost-effective. However, fisheries management is about making choices among alternative policies in the face of uncertainty, and to make an informative choice, a prediction about the consequence of that choice is required (Hilborn and Walters 1992). Our simulation of the trap activation alternative using the reverse-intercept approach indicated that $63 \%$ of the outcomes reduced sea lamprey abundance relative to status quo, with the average outcome resulting in a $7 \%$ reduction in sea lamprey abundance relative to status quo. The GLFC can incorporate risk considerations when considering deployment of pheromonebaited control tactics into the sea lamprey control program by requiring a certain proportion of outcomes to result in reduced sea lamprey abundance, or by using some other metric to explicitly consider risk. Developing and adopting an effective risk policy and assessing and communicating risks associated with a set of management actions could help promote selection of a management strategy that benefits the resource as well as the stakeholders (National Aquarium 2014).

Risk policies should incorporate consideration of risk into the broader context of the probability and severity of consequences associated with future actions (National Aquarium 2014). The adoption of a precautionary reference level of stock reduction was a critical step in allowing MSE methods to be applied in the management of the Antarctic krill fishery (Sainsbury et al. 2000). A required condition of any strategy of the krill fishery, was that median spawner biomass was greater or equal to $75 \%$ of its median pre-exploitation level and had less than a $10 \%$ chance of being below $20 \%$ of its median pre-exploitation level after a 20 year period (Sainsbury et al. 2000). Additionally, reducing the risk to the resource while increasing potential benefits usually occurs when research is undertaken to increase information about a 
fishery (FAO 1996). Reducing risks to the krill fishery could likely be gained through quantitative guidance from predator-prey studies (Sainsbury et al. 2000), while reducing risks resulting from greater sea lamprey abundance due to implementation of a novel control tactic could likely be gained through studies designed to optimize $3 \mathrm{kPZS}$ application to increase trap efficacy.

Before using an MSE to evaluate whether a new tactic should be added to an existing control program, fundamental research aimed at elucidating the nature and function of the tactic must be complemented by research that evaluates its potential to achieve management goals in 'real-world' tests (Li et al. 2003 and 2007; Luehring et al. 2011). Our 'real-world' test was in the Lake Michigan basin, and while we cannot be certain, we suggest that the general trends described next would be transferable to the other Great Lakes. In our example, the most favorable outcome to maximize the efficacy of GLFC control expenditures resulted from our simulations of the trap activation alternative, which assumes that trap efficacy is increased by activating only the water flowing through the trap and not the entire stream discharge. Additionally, for all of the hybrid management strategies tested, MSE revealed increases in trap efficacy were more effective at reducing adult sea lamprey abundance than similar decreases in cost of $3 \mathrm{kPZS}$. This may be because the cost of 3kPZS application to barrier-integrated traps is low as existing traps are operated by control agents regardless of whether $3 \mathrm{kPZS}$ is applied, staff time needed to apply $3 \mathrm{kPZS}$ is minimal, $3 \mathrm{kPZS}$ is effective at low concentrations, and the cost to synthesize $3 \mathrm{kPZS}$ has decreased nearly 40 -fold in the past decade (Johnson et al. 2013). Furthermore, the MSE revealed that the loss of adult sea lamprey that are marked and released and never recaptured can substantially reduce the effectiveness of this novel tactic, or any tactic that aims to remove adult sea lamprey in an effort to reduce subsequent recruitment.

MSE can be valuable when it allows fishery managers to make more informed decisions, including when it helps determine whether investment in alternatives may prove worthwhile. A primary goal of the MSE approach is to assess the performance of different options in balancing multiple and sometimes competing economic, social, and biological objectives (Holland 2010). Thus, our MSE model could be refined, for example, to maximize reductions in adult sea lamprey abundance while minimizing pesticide 
use (to achieve other ecosystem goals and alleviate public concerns). Another use could be to evaluate the trade-offs between the costs of increased production of sea lamprey and the benefits of improved fish passage if an impassable barrier in a Great Lakes tributary were removed to increase lotic connectivity. We have tried in this study (as MSE seeks to do) to provide the decision makers with the information on which to base a rational decision, given their own objectives, preferences, and attitudes to risk (Smith et al. 1999).

Acknowledgements. We thank the University of Michigan-Flint Office of Research for funding this project in part through a Research and Creative Activities Award provided to H. Dawson. Insights and feedback from sea lamprey biologists and managers were crucial to the development of this research project. In particular, Jessica Barber, Gregory Klingler, Jeff Slade, and Michael Twohey answered questions and provided data regarding potential study streams and costs of deployment of pheromonebaited trapping. We thank Norine Dobiesz and Alex Jensen for their assistance in modifying the model for this project. We thank students at University of Michigan-Flint who helped conduct model simulations and prepare this manuscript for publication. In particular, Alexander Maguffee, Anna Darzi, Tyler Main, Jenny Hu, Drew Schaft, Eddy Elkassis, and Adam Brown explored valuable questions using the model. We also thank the previous programmers and users of earlier versions of the sea lamprey operating model. This is contribution No. 1926 of the U.S. Geological Survey Great Lakes Science Center and contribution number XXXX-XX of the Quantitative Fisheries Center at Michigan State University. The Georgia Cooperative Fish and Wildlife Research Unit is sponsored jointly by the U.S. Geological Survey, the Georgia Department of Natural Resources, the U.S. Fish and Wildlife Service, the University of Georgia, and the Wildlife Management Institute. Any use of trade, firm, or product names is for descriptive purposes only and does not imply endorsement by the U.S. Government. 


\section{REFERENCES}

A.N.E. Birch, G.S. Begg, and G.R. Squire [2011], How agro-ecological research helps to address food security issues under new IPM and pesticide reduction policies for global crop production systems, J. Exp. Bot. 62(10), 3251-3261.

N. Bunnefeld, E. Hoshino, and E.J. Milner-Gulland [2011], Management strategy evaluation: a powerful tool for conservation? Trends Ecol. Evol. 26(9), 441-447.

D.S. Butterworth [2007], Why a management procedure approach? Some positives and negatives, ICES J. Mar. Sci. 64(4), 613-617.

H.A. Dawson [2007], Recruitment Dynamics of Great Lakes Sea Lamprey (Petromyzon marinus) Populations and Implications for Integrated Pest Management. Ph.D. Dissertation, Michigan State University, East Lansing, MI.

H.A. Dawson and M.L. Jones [2009], Factors affecting recruitment dynamics of Great Lakes sea lamprey (Petromyzon marinus) populations, J. Great Lakes Res. 35(3), 353-360.

FAO [1996], Precautionary approach to capture fisheries and species introductions, 2nd ed. FAO Technical Guidelines for Responsible Fisheries, FAO, Rome.

Great Lakes Fishery Commission [2011], Strategic vision of the Great Lakes Fishery Commission 2011-2020, Great Lakes Fishery Commission, Ann Arbor, MI.

R. Hilborn and C.J. Walters [1992], Quantitative Fisheries Stock Assessment: Choice, Dynamics and Uncertainty, Chapman \& Hall, New York.

D. S. Holland [2010], Management strategy evaluation and management procedures: tools for rebuilding and sustaining fisheries, OECD Food, Agriculture and Fisheries Working Papers, No. 25, OECD Publishing.

B.J. Irwin, W. Liu, J.R. Bence, and M.L. Jones [2012], Defining economic injury levels for sea lamprey control in the Great Lakes basin, N. Am. J. Fish. Manage. 32(4), 760-771. 
B.J. Irwin, M.J. Wilberg, M.L. Jones, and J.R. Bence [2011], Applying structured decision making to recreational fisheries management, Fish. 36(3), 113-122.

N.S. Johnson, M.J. Siefkes, C.M. Wagner, H.A. Dawson, H. Wang, T.B. Steeves, M. Twohey, and W. Li [2013], A synthesized mating pheromone component increases adult sea lamprey (Petromyzon marinus) trap capture in management scenarios, Can. J. Fish. Aquat. Sci. 70(7), 1101-1108.

N.S. Johnson, W.D. Swink, T.O. Brenden, J.W. Slade, T.B. Steeves, M.F. Fodale, and M.L. Jones [2014], Survival and metamorphosis of low-density populations of larval sea lampreys (Petromyzon marinus) in streams following lampricide treatment, J. Great Lakes Res. 40(1), 155-163.

N.S. Johnson, M.J. Siefkes, C.M. Wagner, G. Bravener, T.B. Steeves, M. Twohey, and W. Li [2015], Factors influencing capture of invasive sea lampreys in traps baited with a synthesized sex pheromone component, J. Chem. Ecol. 41, 913-923.

M.L. Jones and J.R. Bence [2009], Uncertainty and fishery management in the North American Great Lakes: lessons from applications of decision analysis, in (C.C. Krueger and C.E. Zimmerman eds.), Pacific salmon: Ecology and management of western Alaska's populations, Am. Fish. S. S. 70, Bethesda, Maryland.

M.L. Jones, B.J. Irwin, G.J.A. Hansen, H.A. Dawson, A.J. Treble, W. Liu, W. Dai, and J.R. Bence [2009], An operating model for the integrated pest management of Great Lakes sea lampreys, Open Fish Sci. J. 2, 59-73.

W. Li, M.J. Siefkes, A.P. Scott, and J.H. Teeter [2003], Sex pheromone communication in the sea lamprey: implications for integrated management, J. Great Lakes Res. 29(Suppl. 1), 85-94.

W. Li, M. Twohey, M.L. Jones, and C.M. Wagner [2007], Research to guide use of pheromones to control sea lamprey, J. Great Lakes Res. 33(Suppl. 2), 70-86.

M.A. Luehring, C.M. Wagner, and W. Li [2011], The efficacy of two synthesized sea lamprey sex pheromone components as a trap lure when placed in direct competition with natural male odors, Biol. Invasions. 13(7), 1589-1597. 
M.K. McAllister, P.J. Starr, V.R. Restrepo, and G.P. Kirkwood [1999], Formulating quantitative methods to evaluate fishery-management systems: what fishery processes should be modelled and what trade-offs should be made? ICES J. Mar. Sci. 56(6), 900-916.

National Aquarium. 2014, Addressing uncertainty in fisheries science and management. Retrieved April 1, 2015, from http://www.aqua.org/ /media/Files/fisheries-report/addressing-uncertainty-in-fisheriesscience-and-management-report.pdf

A.E. Punt [2006], The FAO precautionary approach after almost 10 years: have we progressed towards implementing simulation-tested feedback-control management systems for fisheries management? Nat. Res. Model. 19(4), 441-464.

K.J. Sainsbury, A.E. Punt, and A.D.M. Smith [2000], Design of operational management strategies for achieving fishery ecosystem objectives. ICES J. Mar. Sci. 57(3), 731-741. doi:10.1006/jmsc.2000.0737.

A.D.M. Smith, K.J. Sainsbury, and R.A. Stevens [1999], Implementing effective fishery-management systems-management strategy evaluation and the Australian partnership approach, ICES J. Mar. Sci. 56(6), 967-979.

E.B. Szalai, J.R. Bence, and M.L. Jones [2005], Estimating sea lamprey damage to fish populations in Lakes Michigan and Huron. Great Lakes Fishery Commission Project Completion Report, Ann Arbor, Mich.

C.M. Wagner and A.F. Thomas [2010], A full-scale field test of the efficacy of the male mating pheromone compound 3-keto-petromyzonal-sulfate in trapping-for-control scenarios, Great Lakes Fishery Commission Project Completion Report, Ann Arbor, Mich.

J.G. Weise and T.A. Pajos [1998], Intraspecific competition between larval sea lamprey year-classes as Salem Creek was recolonized, 1990-1994, after a lampricide application, N. Am. J. Fish. Manage. 18(3), $561-568$. 
TABLE 1. Model parameters and their assumed or calculated values.

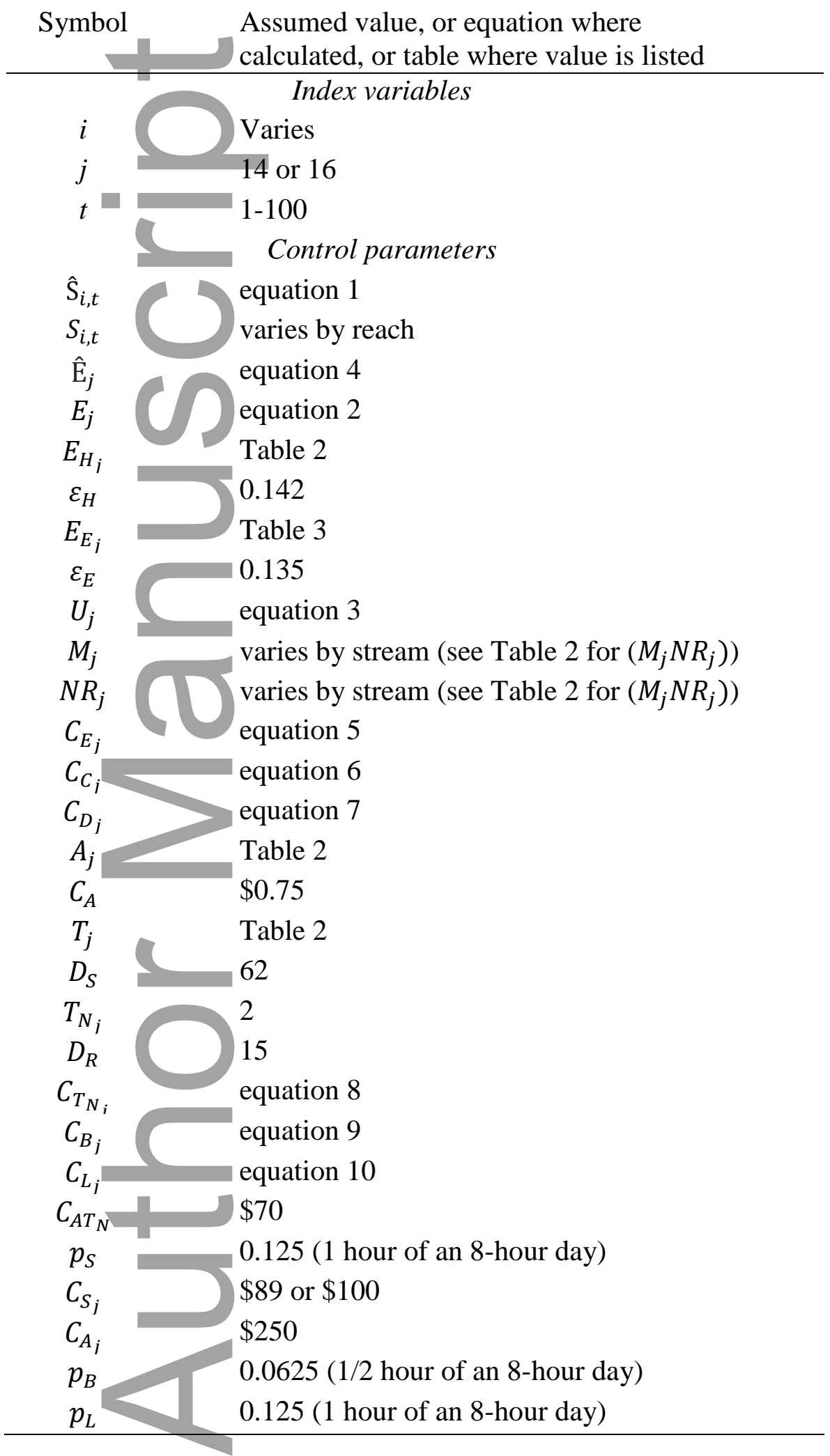


1 TABLE 2. Summary of the 16 currently trapped streams in Lake Michigan with the level of sea lamprey pro

2 number of existing traps, size, historical trap efficacy (TE), proportion of marked animals not recaptured, anc of $3 \mathrm{kPZS}$ applied per day in the stream and trap activation alternatives.

\begin{tabular}{|c|c|c|c|c|c|c|c|}
\hline Stream & $\begin{array}{c}\text { Sea } \\
\text { lamprey } \\
\text { production }\end{array}$ & $\begin{array}{c}\text { Existing } \\
\text { traps } \\
\left(T_{j}\right)\end{array}$ & $\begin{array}{c}\text { Drainage } \\
\text { area } \\
\left(\mathrm{km}^{2}\right)\end{array}$ & $\begin{array}{c}10 \text {-year } \\
\text { average } \\
\text { historical } \\
\mathrm{TE}\left(E_{H_{j}}\right)\end{array}$ & $\begin{array}{c}5 \text {-year } \\
\text { average } \\
\text { proportion } \\
\text { of marked } \\
\text { animals not } \\
\text { recaptured } \\
\left(M_{j} N R_{j}\right)\end{array}$ & $\begin{array}{l}3 \mathrm{kPZS}(\mathrm{mg}) \\
\text { applied per } \\
\text { day in the } \\
\text { stream } \\
\text { activation } \\
\text { alternative } \\
\left(A_{j}\right)\end{array}$ & $\begin{array}{l}3 \mathrm{kPZS}(\mathrm{mg}) \\
\text { applied per } \\
\text { day in the } \\
\text { trap } \\
\text { activation } \\
\text { alternative } \\
\left(A_{j}\right)\end{array}$ \\
\hline Menominee Riyer & Irregular & 1 & 10502 & 0.21 & 0.51 & 1830 & 100 \\
\hline St. Joseph Riv & Irregular & 2 & 9558 & 0.35 & 0.37 & 1760 & 100 \\
\hline Muskegon River & Regular & 2 & 7327 & 0.29 & 0.39 & 1390 & 100 \\
\hline $\begin{array}{l}\text { Big Manistee } \\
\text { River }\end{array}$ & Regular & 2 & 3686 & 0.14 & 0.40 & 670 & 100 \\
\hline Manistique River & Irregular & 5 & 3631 & 0.46 & 0.07 & 500 & 100 \\
\hline Peshtigo River & Regular & 2 & 2845 & 0.74 & 0.11 & 510 & 100 \\
\hline Oconto River & Irregular & 1 & 2155 & 0.41 & 0.89 & 280 & 100 \\
\hline Elk Lake Outlet & Irregular & 2 & 1066 & 0.21 & 0.86 & 250 & 100 \\
\hline $\begin{array}{l}\text { Little Manistee } \\
\text { River }\end{array}$ & Regular & 2 & 732 & 0.59 & 0.38 & 110 & 100 \\
\hline Boardman River & Regular & 2 & 730 & 0.48 & 0.28 & 70 & 100 \\
\hline Betsie River & Regular & 2 & 590 & 0.43 & 0.25 & 120 & 100 \\
\hline East Twin River & Irregular & 1 & 328 & 0.37 & 0.71 & 90 & 100 \\
\hline Jordan River & Regular & 2 & 224 & 0.31 & 0.68 & 90 & 100 \\
\hline Carp Lake Outlet & Irregular & 1 & 117 & 0.52 & 0.13 & 35 & 100 \\
\hline Ogontz River & Regular & 1 & 83 & 0.16 & 0 & - & - \\
\hline Hog Island Creek & Regular & 1 & 19 & 0.37 & 0.74 & - & - \\
\hline
\end{tabular}

4

5

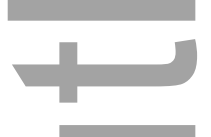

6

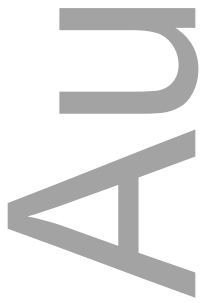

This is the author manuscript accepted for publication and has undergone full peer review but has not been through the copyediting, typesetting, pagination and proofreading process, which may lead to differences between this version and the Version of Record. Please cite this article as doi: $\underline{10.1111 / \mathrm{nrm} .12096 .}$.

This article is protected by copyright. All rights reserved. 
TABLE 3. Summary of the management strategies evaluated by the model with associated baited or unbaited traps, 3kPZS application rate per trap, and the current estimates of increase in

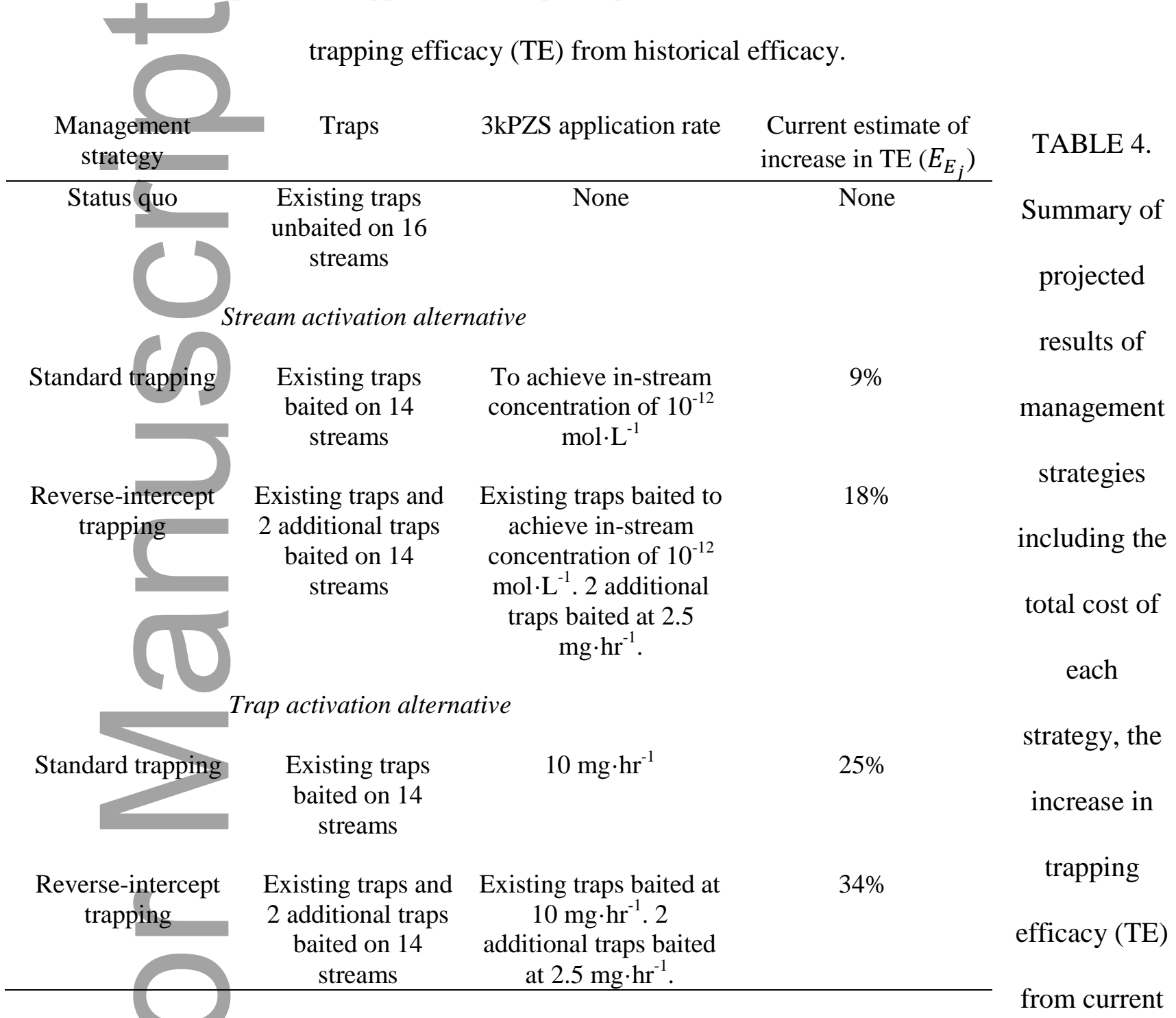

estimates to achieve status quo control, a $10 \%$ reduction from status quo, and the percentage of simulations at current estimates in years 91-100 with a projected abundance of adult sea lamprey

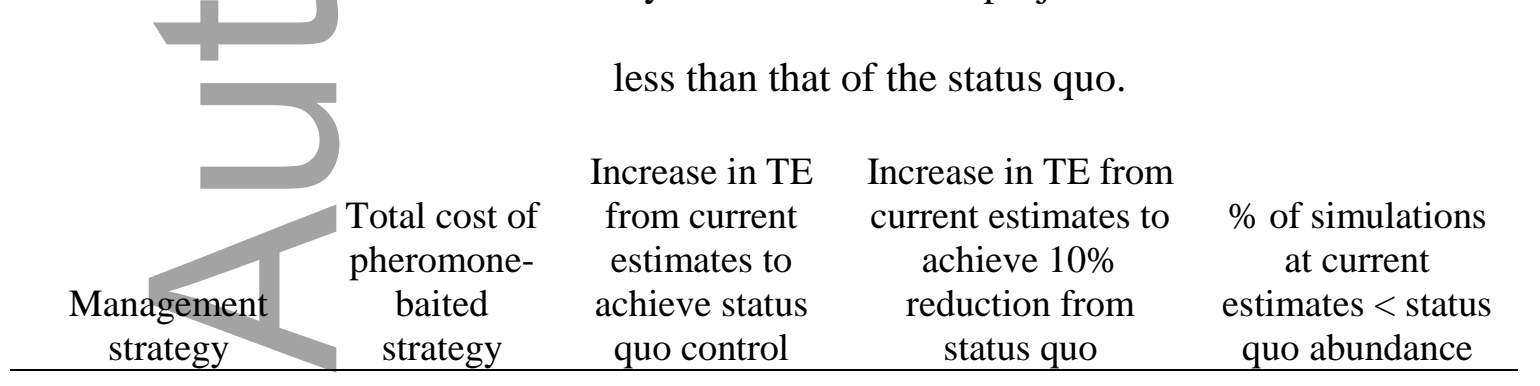

This is the author manuscript accepted for publication and has undergone full peer review but has not been through the copyediting, typesetting, pagination and proofreading process, which may lead to differences between this version and the Version of Record. Please cite this article as doi: $\underline{10.1111 / \mathrm{nrm} .12096 .}$.

This article is protected by copyright. All rights reserved. 


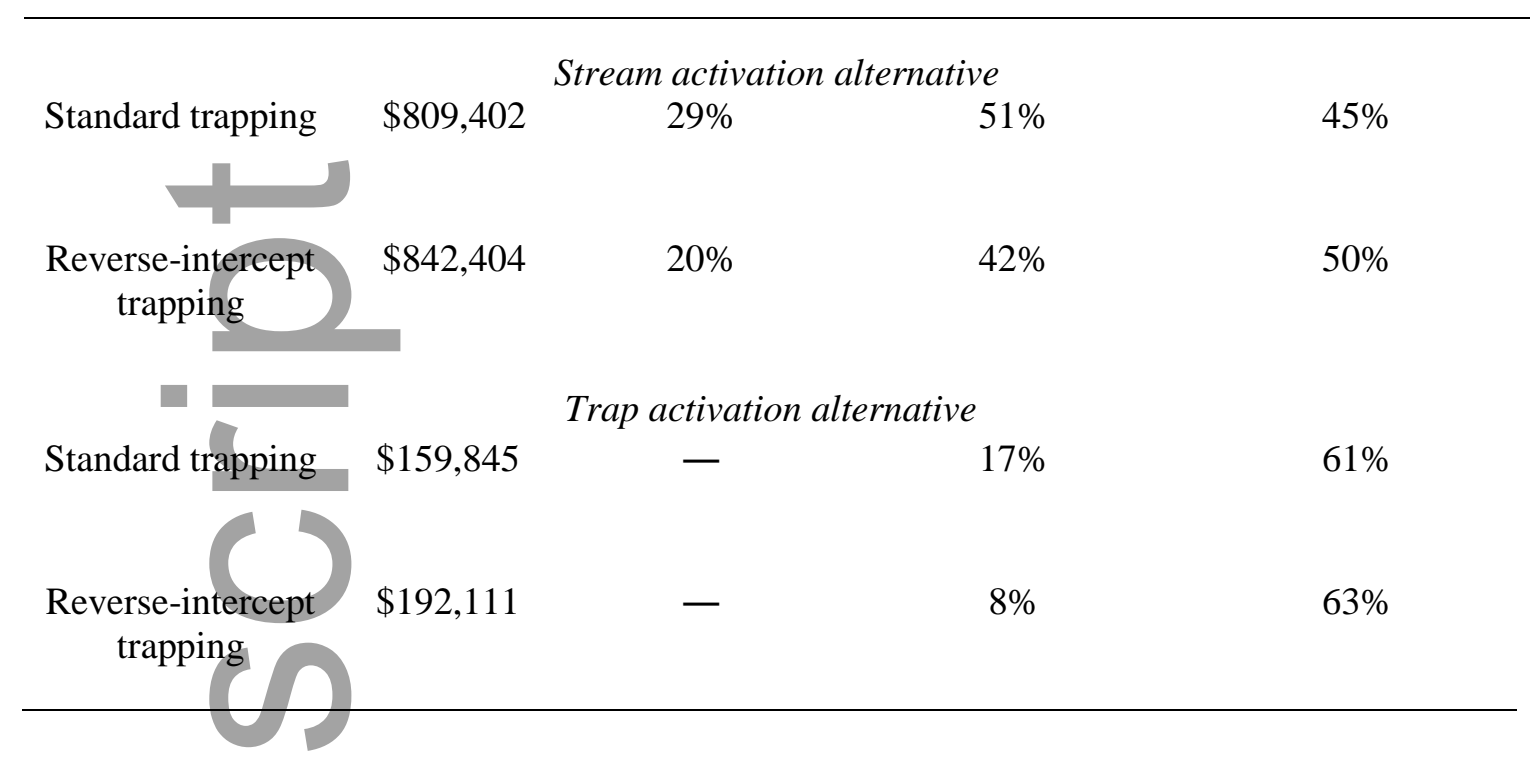

\section{Figure captions}

FIGURE 1. A map of Lake Michigan showing the location of fourteen streams (solid circles) in which the deployment of pheromone-baited trapping was simulated and the location of fourteen streams and an additional two streams (solid triangles) in which status quo management was simulated.

FIGURE 2. The distribution of 5000 simulated adult sea lamprey abundances in Lake Michigan for the status quo option, the stream activation alternative, and the trap activation alternative. The stream and trap activation alternative are shown when standard trapping was deployed (light gray boxes) and reverseintercept trapping was deployed (dark gray boxes). Boxes contain the 25 th and 75 th percentiles, the median value is identified with a solid horizontal line, whisker bars are the 10th and 90th percentiles, solid circles are the 5th and 95th percentiles, and a dashed line indicates mean values. The dashed horizontal line indicates the mean adult sea lamprey abundance under status quo management.

\section{SUPPORTING INFORMATION}

The following supporting information is available for this article.

APPENDIX 1: Adjustments to observation and management models since models were described in Jones et al. (2009). 


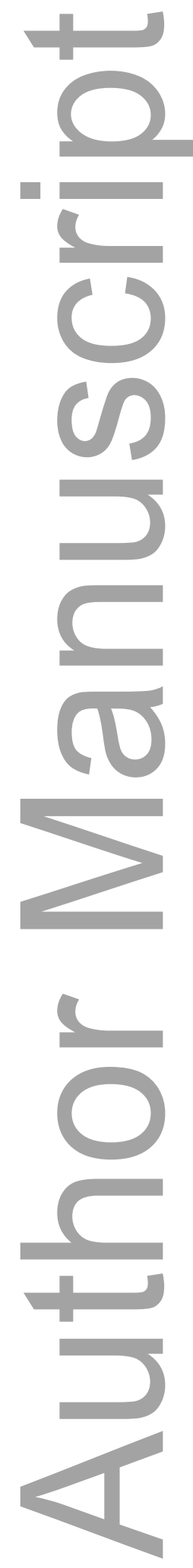

This article is protected by copyright. All rights reserved. 


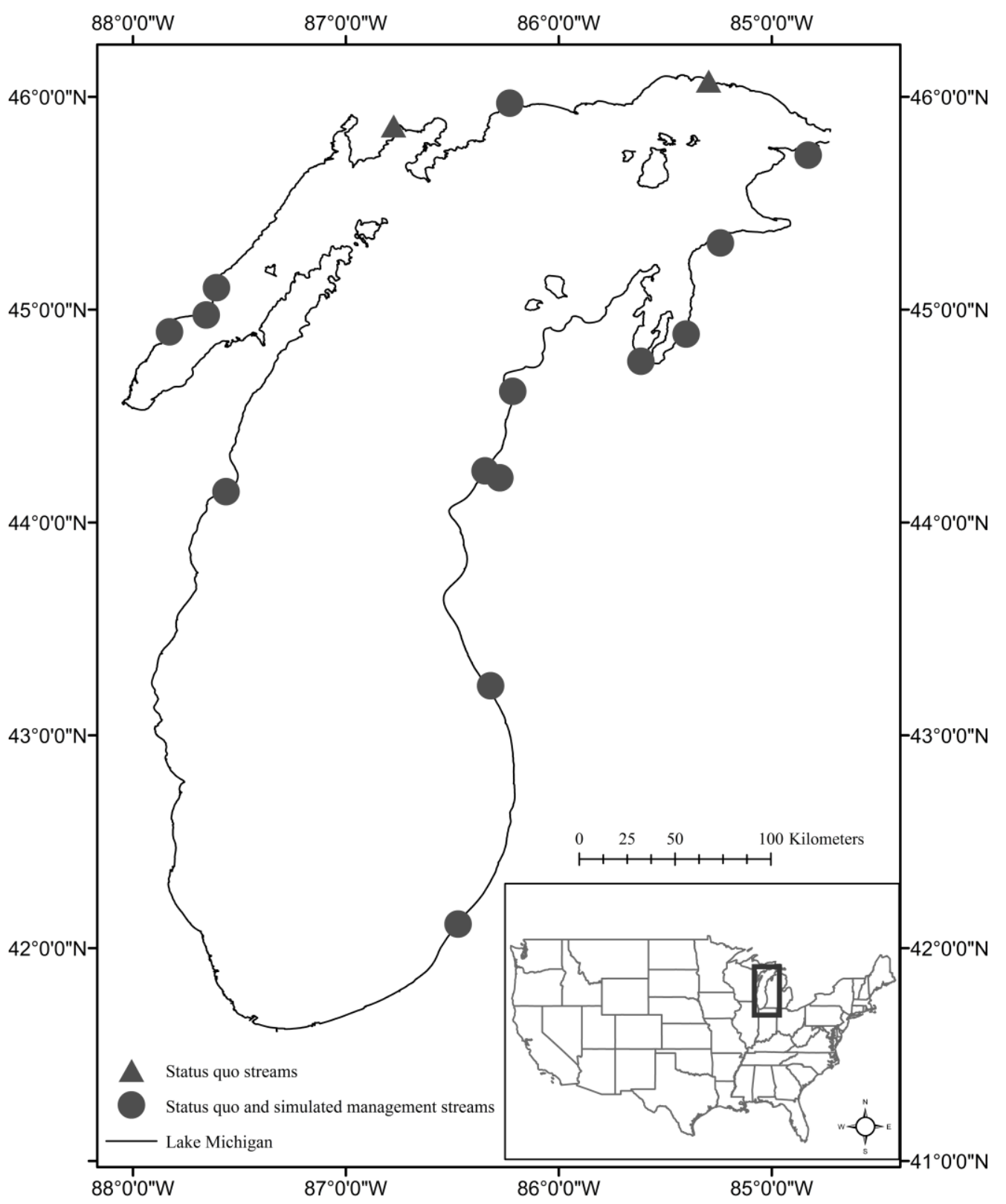

This article is protected by copyright. All rights reserved. 

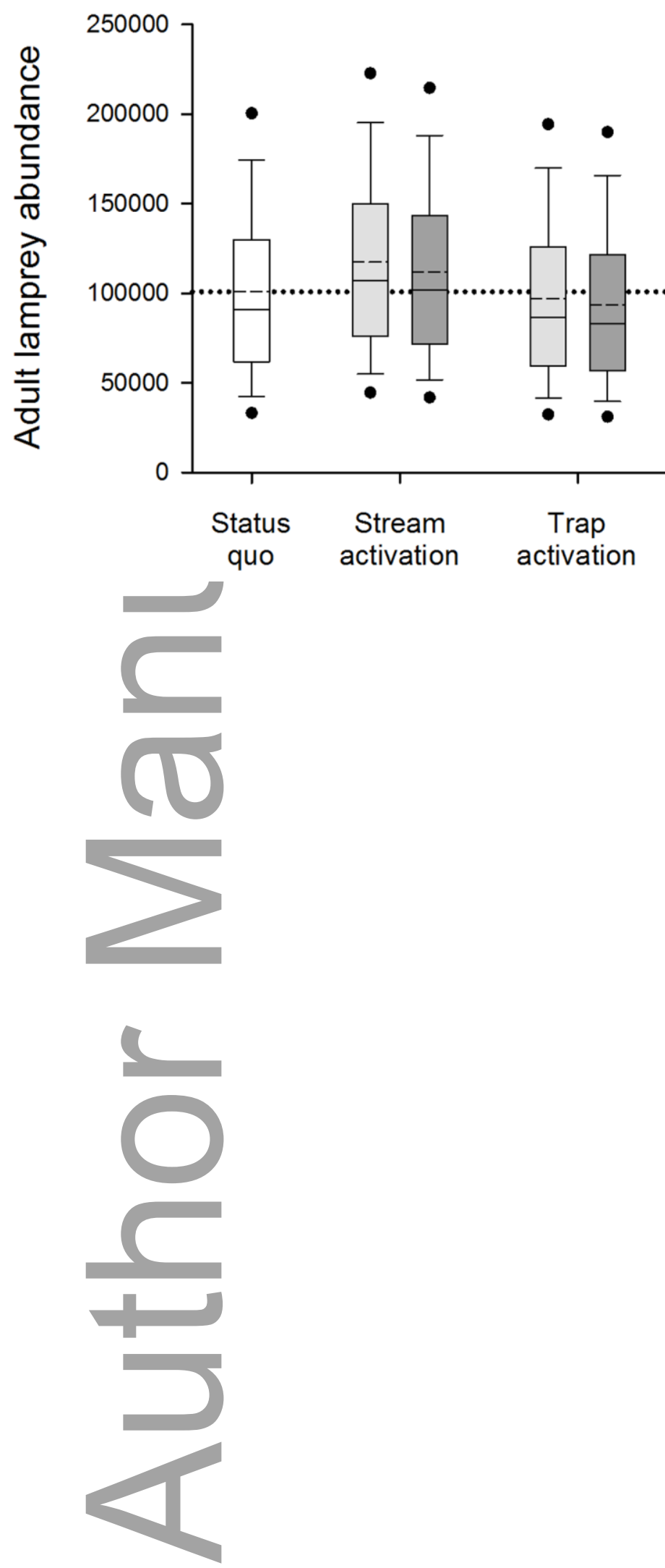

This article is protected by copyright. All rights reserved. 